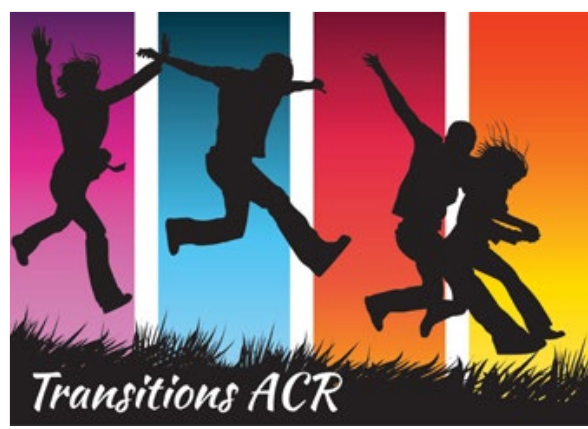

Volume 17, Issue 14

\title{
Should I Attend College in the Fall? Questions for Students with Mental Health Conditions to Consider
}

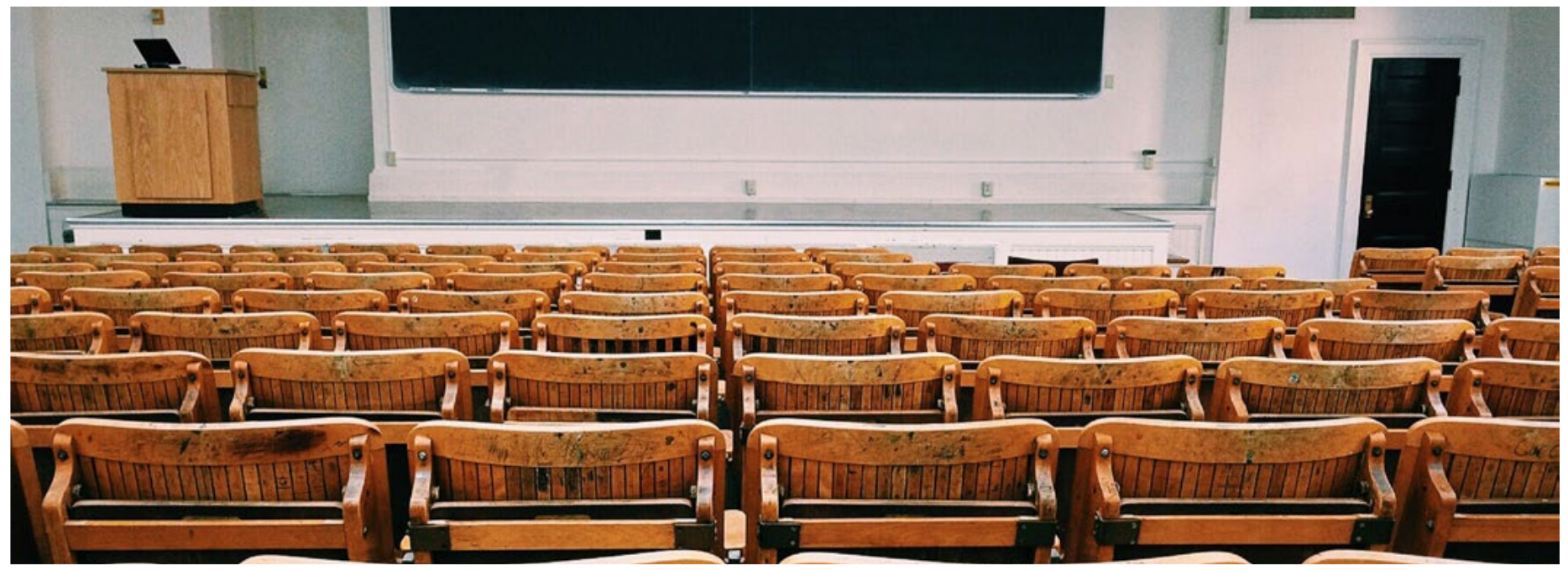

The following questions are intended to help students with mental health conditions, their supporters, and loved ones make decisions about whether to return to college this fall. Your school has probably answered many of the basic questions for you regarding physical safety, finances, schedules, etc. But these are questions schools may not have addressed that may be helpful to think about when making the right decision for yourself. These questions may lead you to contacting your school for more information.

\section{Things to consider if you are a college student with a mental health condition}

- How was my experience in the Spring semester when we transitioned online? Did online learning work for me? If not, why?

- How do the symptoms I have or medications I take for my mental health condition impact the way I learn? How do I best learn? What types of support/resources do I need to do the best that I can?

- Can I navigate and organize my virtual classes? Can I organize and maintain my online class schedule/todos on my own, with virtual learning?

- Do I have the equipment I need to be successful in my upcoming online classes?

- Are the classes I registered for in the Fall particularly challenging for me in an online format?

- Do I need the resources, including health insurance, that my college offers to maintain my wellness? And if so, can I get them virtually or do I need in-person support? How could I make this work?

- Think about what happens for you when things get hard. How would I handle these times if I'm not on campus? Or if I'm on campus with new distancing rules in place?

- Can I do a good job advocating for myself with roommates or dorm mates if I have concerns about safety protocols? 
For students who go away to school: What are the benefits of staying local and going to a community college for the Fall semester?

\section{Questions to ask your school}

\section{Coursework}

- How are online classes being made accessible for students with learning differences and/or mental health conditions?

- What will be provided to the students who struggle with learning online?

- Will academic resources be expanded to help me if I struggle with virtual learning? Can they be personalized? Can they be in-person?

- What are the standards being used for online instructions?

- How is the school ensuring that the educational quality is the same as before?

- What type of formal process has the school put in place to solicit student input/feedback about organization of coursework and professor responsiveness?

\section{Support Services}

- What will mental health services look like in the Fall semester? Will there be a combination of in-person and tele-health options? How will they be accessible to students who are not on campus?

- What specialized services are being put into place to help students who are returning online and have a disability?

- What is the process to request accommodations when classes are online?

\section{If l'm thinking about taking the semester or year off from school or deferring my}

\section{admission}

- What experiences will I be missing as a student? How do I feel about it? Do the pros of returning to school outweigh the cons?

- Can I live with the uncertainty of not exactly knowing when l'll get back to college?

- Will taking time off from school for a semester (or year) have consequences? Will I have to reapply? Will I lose some momentum? What happens to financial aid/scholarships?

- What other options do I have? What else can I do to contribute to my career development? What will help me progress in my career plans?

- Am I capable of keeping myself on track? Who can help me?

- How will I build some structure into my life? Job, internship, volunteer work? Online certifications in programs of interest? Do I have the resources and capacity to engage in one of these?

- Can I put together a concrete plan on how I will fulfill my intellectual and social needs? "On a daily basis I will..." Are school advisors available to help?

- What other things can I do to continue to learn? (For instance, certified in Microsoft Office, take a personal finance program, learn a programming language, take skills assessment or career profile tests, etc.) 
Once you thoughtfully review these questions, the answer as to how you should handle this upcoming semester may be obvious to you. If not, a decision matrix like this one can help.

Decisional Balance Worksheet for Returning to School Fall 2020

I am considering whether or not I am going to school in the fall.

\begin{tabular}{|c|c|c|}
\hline & PROS OR BENEFITS & \\
\hline & & \\
GOING TO & & \\
SCHOOL IN & & \\
FALL & & \\
2020 & & \\
\hline & & \\
NOT GOING & & \\
TO SCHOOL & & \\
IN FALL & & \\
2020 & & \\
& & \\
\hline
\end{tabular}

Helping Youth on the Path to Employment www.umassmed.edu/HYPE 


\section{Resources}

There are many more questions you can ask yourself and your school to help you make the right decision for yourself. Here are some resources to assist you.

- 5 Bigger and Better Ideas for Fall 2020 - https://www.insidehighered.com/views/2020/07/20/collegeleaders-should-consider-some-outside-box-ideas-fall-2020-opinion

- Colleges Spent Months Planning For Fall, But A COVID-19 Surge Is Changing Everything - https:// www.npr.org/2020/07/22/893525083/colleges-spent-months-planning-for-fall-but-a-covid-19-surge-ischanging-everyth

- Going back to college during a pandemic: Here's what you need to know - https://www.latimes.com/ lifestyle/story/2020-07-09/going-back-to-college-during-a-pandemic-heres-what-you-need-to-know

- 7 ways the coronavirus pandemic could change college this fall and forever - https://www.cnbc. com/2020/06/19/7-ways-coronavirus-pandemic-may-change-college-this-fall-and-forever.html

- Should you attend college next fall? Before deciding, here are all the questions you should NOT be afraid to ask - https://www.marketwatch.com/story/should-you-attend-college-next-fall-beforedeciding-here-are-all-the-questions-you-should-not-be-afraid-to-ask-2020-06-04

- You Have Been Accepted To College For The Fall. Should You Go? - https://www.forbes.com/ sites/lucielapovsky/2020/05/31/you-have-been-accepted-to-college-for-the-fall-should-yougo/\#7dd8f433433d

- Decision-Making: Link to Mental Health \& Wellbeing - https://www.rehabs.com/pro-talk/decisionmaking-link-to-mental-health-wellbeing/

\section{Acknowledgements:}

The Transitions ACR would like to send a very special thanks to our Family Advisory Board who helped in the development of this tip sheet.

Recommended Citation: Mullen, M. G., \& Wnuk, J. (2020). Should I Attend College in the Fall? Questions for Students with Mental Health Conditions to Consider. Worcester, MA: University of Massachusetts Medical School, Department of Psychiatry, Implementation Science and Practice Advances Research Center (iSPARC), Transitions to Adulthood Center for Research.

The contents of this tip sheet were supported in part under grants with funding from the National Institute on Disability, Independent Living, and Rehabilitation Research, (NIDILRR), United States Departments of Health and Human Services (NIDILRR grant number 90RTEM0005, The Learning and Working Transitions RRTC). NIDILRR is a Center within the Administration for Community Living (ACL), Department of Health and Human Services (HHS). The contents of this tip sheet do not necessarily represent the policy of NIDILRR, ACL, or HHS and you should not assume endorsement by the Federal Government.

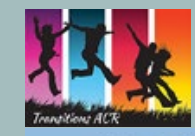

This publication can be made available in alternative formats upon request through TransitionsACR@umassmed.edu

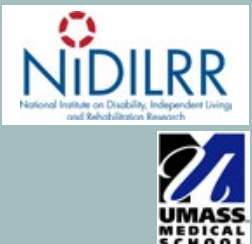

